REVIEW

\title{
Stability of Supported Liquid Membranes: State of the Art
}

\author{
A. J. B. KEMPERMAN, ${ }^{*}$ D. BARGEMAN, \\ Th. VAN DEN BOOMGAARD, $\dagger$ and H. STRATHMANN \\ MEMBRANE TECHNOLOGY GROUP \\ DEPARTMENT OF CHEMICAL TECHNOLOGY \\ UNIVERSITY OF TWENTE \\ P.O. BOX 217. NL-7500 AE ENSCHEDE, THE NETHERLANDS
}

\begin{abstract}
This paper presents a state of art review on the stability of supported liquid membranes (SLM). The backgrounds of SLM instability phenomena are presented, and various mechanisms for explaining these phenomena are treated in detail. Several suggestions for stability improvement are discussed.
\end{abstract}

\section{INTRODUCTION}

Supported liquid membranes (SLMs) are a promising alternative to liquid-liquid extraction and other (membrane) separation techniques for the selective removal of ions or neutral molecules from solutions and gases. In most membrane processes like, e.g., reverse osmosis, ultrafiltration, or microfiltration, the solvent and various solute particles permeate through the membrane while other molecules or particles are rejected. To transport the permeate through the membrane, a certain amount of energy has to be supplied. SLMs are different, since in this case only the component to be separated is transported. This fundamentally different approach for separation can be much more energy efficient.

* Present address: Agrotechnological Research Institute (ATO-DLO), Fatty Acid and Membrane Technology, P.O. Box 17, NL-6700 AA Wageningen, The Netherlands.

$\dagger$ To whom correspondence should be addressed (A.vandenBoomgaard(act.utwente.nl). 
SLMs usually consist of an organic solvent, immobilized in the pores of a hydrophobic microfiltration membrane. In general, the organic solvent contains a carrier which binds one of the components very selectively in the feed solution. Furthermore, the organic phase might contain a modifier which favors the extraction of a certain selected species in a synergistic fashion and improves the selectivity of the SLM in this way (1). Because transport takes place in a liquid fluxes for not too small molecules are higher compared to "solid" polymeric membranes since diffusion coefficients in liquids are in general orders of magnitude higher than in solid materials. Another advantage of SLMs is the high selectivity of the process when a proper selective complexing agent is chosen as carrier. Furthermore, it is possible to separate and concentrate species at the same time, i.e., liquid membranes are capable of providing cocurrent and countercoupled transport. Other advantages of SLMs are the modest capital and operating costs, the low energy consumption, and the possibility of using expensive extractants $(2,3)$.

Despite the above-mentioned advantages, supported liquid membranes are not used at a large scale in industry nowadays. The major reason for this is the membrane stability or lifetime, which is in general far too low to assure good commercial application possibilities. Instability of SLMs is due to the loss of carrier and/or membrane solvent from the membrane phase which has an influence on both flux and selectivity of the membrane (2-7). Depending on the amounts of carrier and solvent lost from the support pores, the solute flux might either increase, decrease. or stay almost equal. When all LM phase is lost, the membrane breaks down and a direct transport between the two phases adjacent to the liquid membrane takes place with a complete loss of selectivity. The time period after which instability phenomena are observed varies from less than one hour $(5,8)$ to several months $(3,9-11)$ depending on the system.

It is not uniformly stated in the literature under what conditions a liquid membrane is considered to be (in)stable and in which way the (in)stability of a membrane is measured. Most of the authors consider a flux or permeability decrease of the transported species to be an indication for membrane instability (e.g., Refs. 4, 6, 7, 10, 12). However, several other authors claim their membranes to be stable when a constant flux is obtained by replacing the removed liquid membrane phase continuously by fresh LM solution (13-17) or simply state their system is reliable without any further details (18). Sometimes, a significant decrease in selectivity is used to measure instability of a membrane (19-21). To determine stability of liquid membranes, factors like a volume flux of water through the membrane $(5,22-24)$, a rapid increase in $\mathrm{pH}(25)$, or interfacial properties such as the contact angle or a so-called "progressive wetting time" (26) are 
used. However, often no attention at all is paid to the stability of the SLM system.

Separations and enrichments possible with (supported) liquid membranes are described in several excellent review articles and books (6, 27-33). In this paper a critical state of the art literature review will be given on the stability of SLMs. In the following section the causes of SLM instability will be discussed. We restrict ourselves to the removal of components from liquids and do not treat the more specific instability problems for liquid membranes for gas separation or fixed-site carrier membranes. Then several ways for improving the stability of SLMs are presented. Finally, various other configurations for liquid membranes are discussed in detail.

\section{MECHANISMS OF SLM DEGRADATION}

The reason for a supported liquid membrane to become instable is the loss of LM phase (carrier and/or solvent) out of the pores of the support. This loss of carrier and/or membrane solvent can be due to

1. Pressure difference over the membrane

2. Solubility of carrier and membrane solvent in adjacent feed and strip solutions

3. Wetting of support pores by the aqueous phases

4. Blockage of support pores by precipitation of the carrier or by water

5. Presence of an osmotic pressure gradient over the membrane

6. Emulsion formation of the LM phase in water induced by lateral shear forces

These proposed mechanisms of SLM destabilization will be discussed separately.

\section{Pressure Difference over the Membrane}

Due to streaming of solutions across the SLM, a pressure difference might exist over the membrane $(3,5)$. This pressure effect is of special importance when hollow fibers are used as support (19). When the pressure difference exceeds a certain critical value, the liquid membrane phase is pushed out of the pores of the support. Zha et al. defined the critical displacement pressure $P_{c}$ for an SLM as the minimum transmembrane pressure required to displace the impregnating phase out of the largest pore $(6,34)$. For a cylindrical capillary, $P_{\mathrm{c}}$ can be calculated using the Laplace equation:

$$
P=\frac{2 \gamma \cos \theta}{r}
$$


where $P$ is the pressure $\left(\mathrm{N} \cdot \mathrm{m}^{-2}\right), \gamma$ is the interfacial tension between strip or feed solution and the liquid membrane phase $\left(\mathrm{N} \cdot \mathrm{m}^{-1}\right), \theta$ is the contact angle between the membrane pore wall and the impregnating liquid, and $r$ is the pore radius $(m)(35)$. This equation is also used in the determination of the pore size distribution of ultrafiltration membranes using the liquid displacement method (36). The critical displacement pressure $P_{\text {c }}$ can be calculated by stating $\cos \theta$ equals unity. However, Eq. (1) is only valid for cylindrical capillaries while SLM supports usually are highly irregular in geometry. Zha et al. derived an equation for the estimation of the critical displacement pressure for SLMs in such cases. By establishing a so-called "neck model" for the membrane pores, the deviation of the support pores from cylindrical capillaries was taken in consideration. Comparison of their experimental data with the calculated values showed a good agreement. The measured critical displacement pressures for Accurel supports (nominal pore size $0.2 \mu \mathrm{m}$ ) were between 50 and $250 \mathrm{kPa}$, depending on the system. As long as the transmembrane pressure is smaller than the critical pressure, the liquid membrane phase will not be replaced by the aqueous feed or strip solutions. Pulsations of the feed and strip fluxes, in addition to transmembrane pressure gradients, surely will affect membrane stability: due to the loss of carrier and solvent, the flux will decrease. Pressure differences across the membrane as small as $0.2 \mathrm{kPa}$ were shown to be high enough to cause water leakage in flat polytetrafluoroethylene (PTFE) supports (pore size $2.0 \mu \mathrm{m}$ ) filled with toluene, as was experimentally determined by Takeuchi et al. (5). To obtain a stable liquid membrane, transmembrane pressure differences including fluctuations should be minimized. When pressure differences are avoided, SLMs still show instability phenomena $(2,4)$, which indicates that pressure differences are not the main cause of SLM degradation.

\section{Solubility of Carrier and Membrane Solvent}

In case a chemical potential difference $\Delta \mu$ between the liquid membrane and the aqueous phases is present for a carrier and/or an organic solvent (e.g., when the phases are not saturated with the LM phase), there is a driving force for the LM components to dissolve in the aqueous phases, which is the case in many actual operation conditions since one is striving for a continuous process in practice. The solubility greatly influences membrane lifetime when membrane solvent or carrier has a significant solubility in the adjacent aqueous phases. The higher the partition coefficient toward the aqueous phases, the shorter the membrane lifetime (3-5, $14,20,24,25,37-39$ ). Danesi et al. found that the lifetime of SLMs containing acidic carriers like HDEHP, di-(2-ethylhexyl)phosphoric acid, de- 
creased when one of the aqueous solutions had a high $\mathrm{pH}$ (3). This is in agreement with the increased solubility of this type of carrier in water with increasing $\mathrm{pH}$. Due to the high solubility of their membrane solvent, 2-ethylhexyl alcohol, in water $(\sim 0.1 \mathrm{wt} \%)$, Tanigaki et al. observed a rapid decrease in phenol flux (14). Pre-saturation of the aqueous feed and strip phases with the organic phase improved membrane lifetime. However, a rather constant flux for longer time ( 9 days) could only be obtained when the support was continuously reimpregnated with LM phase in the case the aqueous phases were not pre-saturated. The effect of membrane solvent solubility in water and volatility on membrane stability was investigated by Lamb et al. (37). It was observed that the membrane stability increased as the boiling point of the solvent increased or water solubility decreased. The same was found by Deblay et al.: when the solubility of the organic solvent in water was higher than $30 \mathrm{ppm}$, the membrane was instable (lifetime lower than 10 hours) (20).

The solubility of the carrier in the adjacent aqueous phases is also of importance, as was shown by Chiarizia (25). Three different, commercially available long chain aliphatic amines (a primary, secondary, and tertiary one) were tested as carriers for the removal of several ions from synthetic groundwater. Stability decreased in the order tertiary $>$ secondary $>$ primary amine. Solubility of the carrier in water decreased in the order primary $>$ secondary $>$ tertiary amine, opposite to the stability order: the higher the carrier solubility, the lower the membrane stability. Dozol et al. determined aqueous solubilities and SLM lifetimes for a large number of membrane solvents ("diluents") (24). Membrane lifetimes over 200 hours could be obtained when solvents with a water solubility lower than $12 \mathrm{~g} \cdot \mathrm{L}^{-1}$ were applied. Bloch et al. prepared solvent membranes using PVC as polymer, plasticized with phosphate esters which acted as carrier for metal ions (38). Dissolution of the plasticizer in the adjacent aqueous solutions and subsequent impermeability of their solvent membranes was considered to be the cause of membrane failure.

Several authors claim an improvement of SLM lifetime when the aqueous phases are pre-saturated with the organic phase $(11,14)$. Others, however, claim the opposite. Takeuchi et al. found no or only little effect on SLM lifetime when the aqueous phases were pre-saturated with the membrane solvent (5). Neplenbroek et al. pre-saturated the aqueous phases with decanol, but the amount of LM phase removed was independent of the saturation (4), in agreement with the results of Takeuchi et al. Both argue that the breakdown of an SLM is not caused by the solubility of the LM phase components. However, the solubility in their system is probably not the most important mechanism, but in other systems investigated the solubility may play an important role. 


\section{Wetting of the Support Pores by the Aqueous Phases}

This mechanism for SLM degradation was first proposed by Danesi et al. (3) and worked out in detail by Takeuchi et al. $(5,26)$. As a result of, e.g., the formation of metal complexes, contamination of the interface between organic phase and aqueous phases or dissociation of the carrier, both the interfacial tension (between the aqueous phase and the organic phase) and the contact angle (between the aqueous phase and the porous membrane wall) might decrease in time. When the interfacial tension has decreased to below a certain level, the aqueous phases might enter the membrane pores and replace the organic LM phase, according to Takeuchi et al. (26).

To investigate this wetting phenomenon, Takeuchi et al. measured contact angles and interfacial tensions of aqueous drops (solutions of metal ions) lying on macroporous sheets submerged in organic solutions containing a carrier (see Fig. 1) (26). The contact angle $\theta$ as defined by Takeuchi (between the aqueous solution and the membrane) is different from that in Eq. (1) where we defined it as the angle between the membrane pore wall and the impregnating liquid. However, the use of the change in time of the contact angle, in order to determine the critical interfacial tension at which penetration of the aqueous phase in the pores starts, is not allowed for (highly) porous materials, as was pointed out by Franken et al. (40). The results of Takeuchi et al. are therefore doubtful. Furthermore, when this wetting mechanism is valid, the LM phase lost should have the same chemical composition as the remaining liquid in the pores. Neplenbroek et al. found by a careful analysis of the remaining LM phase that this was not the case: carrier and solvent were lost to the aqueous phases

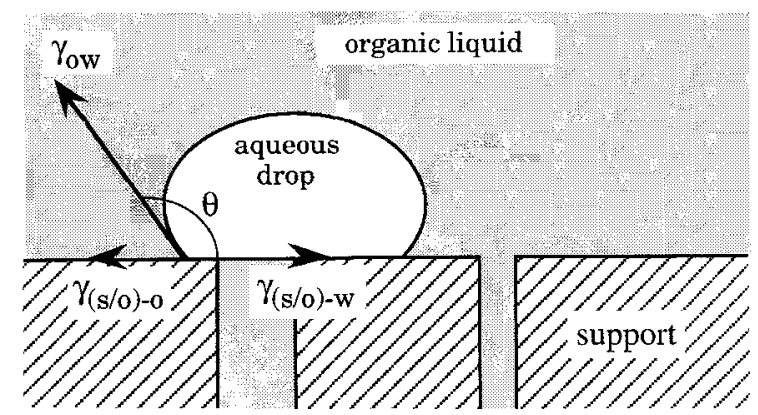

FIG. 1 Schematic drawing of an aqueous drop on a horizontal porous sheet submerged in an organic solution. Adapted from Takeuchi et al. (26). $\gamma=$ interfacial tension, $\theta=$ contact angle (aqueous phase/membrane phase), $\mathrm{o}=$ oil, $\mathrm{w}=$ aqueous solution, $\mathrm{s}=$ porous solid. 
in different ratios (4). So, this mechanism for LM instability is not of major importance.

\section{Pore-Blocking Mechanism}

"Fouling" and subsequent blocking of the support pores can occur in two ways, i.e., by carrier precipitation and by water blockage. Precipitation of carrier molecules in the pores was observed by Belfer et al. for calcium-phosphinic acid complexes (41) and by Chiarizia for long chain aliphatic amines $(25,42)$. Nitrate-trilaurylamine salts were thought to precipitate locally in the membrane pores. The formation of solid or gelatinous precipitates in the pores, beyond the saturation limit in the liquid membrane phase, slows down the diffusion rate of the permeating species. On the other hand, according to Chiarizia, this precipitation might enhance SLM stability by preventing the formation of emulsions with the aqueous phase and by acting as a barrier against water bridging in semidevoid pores (25). Both water channeling and emulsion formation will be discussed later.

Babcock et al. observed a gradual copper flux decay with time and attributed this flux decay to blockage of membrane pores by water (43, 44). This mechanism was also used by Baker and Blume, who called it "spontaneous emulsification" (31). However, this term is only applicable for the spontaneous formation of microemulsions, which is impossible in SLMs due to the relatively high interfacial tension. For the spontaneous formation of emulsions without additional energy, very small interfacial tensions (smaller than $0.01 \mathrm{mN} \cdot \mathrm{m}^{-1}$ ) are required $(45,46)$, much lower than the interfacial tensions usually encountered in LM systems. This term is therefore incorrectly used. The process according to Baker et al. is schematically drawn in Fig. 2 (31). One preliminary remark is that the way the meniscus is drawn by Baker and Blume is not correct: the LM phase will never enter the pores spontaneously if the meniscus has this shape since the contact angle between the impregnating phase and the membrane wall is larger than $90^{\circ}$.

It was thought that water could enter the organic phase at the surface of the membrane and replace the organic phase. The formation of micelles by the carrier molecules, thereby solubilizing water, might result in the introduction of water in the organic phase. Zhu and Li claimed this solubilization of water by micelles to be the reason for water uptake in their SLMs (47). However, they give no experimental proof at all for the existence of these micelles. Furthermore, such micelles are small in general, and it is therefore doubtful whether sufficiently large quantities of water can be introduced into the organic phase. In contradiction to the results 


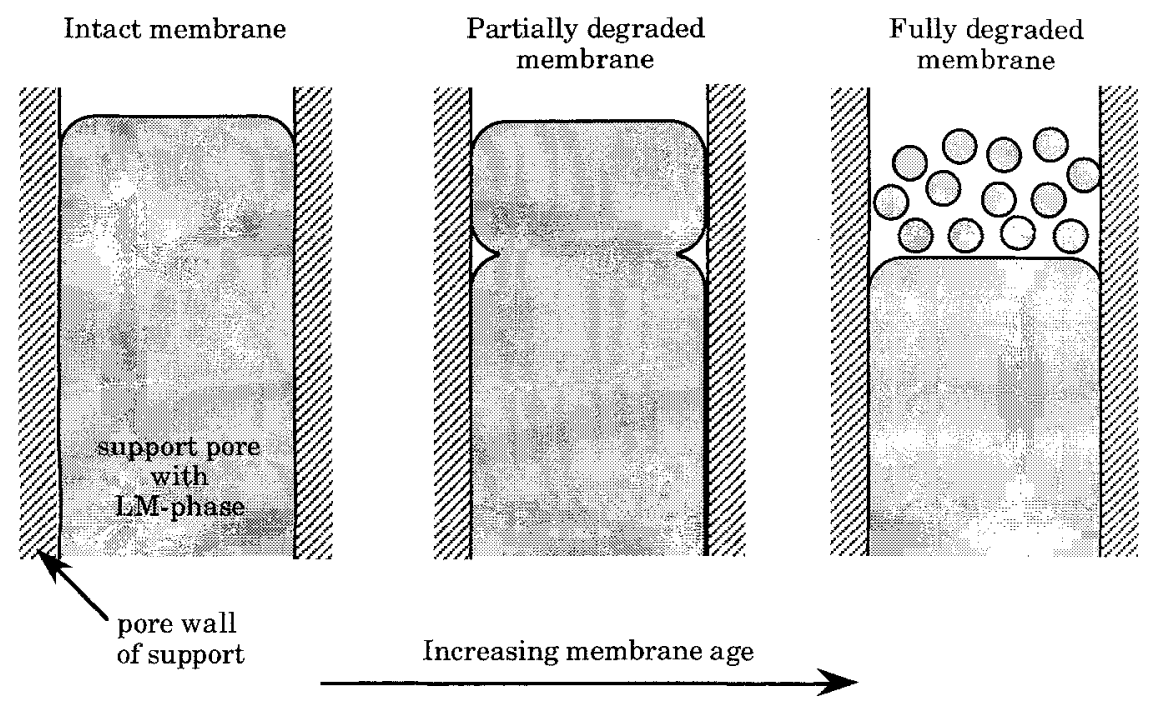

FIG. 2 Schematic drawing of SLM degradation by the formation of an interfacial emulsion. Adapted from Baker et al. (31).

of $\mathrm{Zhu}$ and $\mathrm{Li}$, no water droplets or micelles with solubilized water in decayed SLMs were detected by Zha by gas chromatography, and he therefore rejected the pore-block mechanism for his system $(6,7)$. The intrusion of water into the organic phase is not clear for situations where the formation of micelles in the membrane is impossible. Babcock et al. suggested that the hydrophobic membrane pore wall could be wetted by the aqueous phase due to a change in the contact angle $\theta$ between the organic phase and water, e.g., when the surface-active carrier is lost to the aqueous phases by solubility effects $(43,44)$. When the micelles break up or when the organic phase pulls away from the pore walls, organic droplets are formed. Nevertheless, this is very doubtful. It is not explained how the micelles can break up spontaneously. Furthermore, there will always be a driving force to minimize the surface area, and without the supply of extra energy it is not likely that an extra area is created to form small LM-phase droplets.

The "fouling" was believed to propagate from the strip side of the membrane to the feed side, but again the driving force for this process is ambiguous. Furthermore, the word "fouling" is somewhat misleading, since usually fouling is associated with the (ir)reversible deposition of retained particles, macromolecules, or salts on or in the membrane (48). 
Due to the presence of organic droplets surrounded by the aqueous phase in the support pores, the transport of permeants is hindered. As a result, the flux decreases. Experiments with five pieces of membrane laminated together showed that the flux decay indeed was largest near the aqueous strip side. Also, interfacial tensions between the LM and aqueous phases are so large that spontaneous emulsion formation is not likely to occur $(4,39)$. Finally, another objection against this mechanism is that it does not explain why the ratio of carrier to organic solvent loss to the adjacent aqueous solutions was different from that in the initial membrane liquid as found in Babcock's experiments and by Neplenbroek et al. (4). The correctness of the pore-blocking mechanism is therefore very doubtful.

\section{Osmotic Pressure Effect}

The osmotic pressure effect as a mechanism of SLM degradation was developed independently by Fabiani et al. (23) and Danesi et al. (12). The effect was also proposed by several other authors as one of the causes of SLM instability $(11,20,24,25,29,33,49)$. Fabiani et al. measured water flows and salt fluxes through SLMs separating two $\mathrm{LiCl}$ solutions at different concentrations. There were no hydrostatic pressure gradients applied to the membrane (23). When the osmotic pressure difference $\Delta \Pi$ increased, the water transport increased. According to the authors, as a consequence of the volume flux across the membrane, the organic phase is dragged out of the pores of the support and the SLM becomes unstable.

An impressive piece of work dealing with the lifetime of several supported liquid membranes for metal ion transport, and in particular the influence of osmotic pressure gradients, was published by Danesi et al. (12). The relation between membrane lifetime and several physical properties of the system was investigated. The stability of the membrane was measured by determining the salt permeation and water transport through the membrane as a function of time. The water transport was measured by means of horizontal, calibrated glass tubes attached to the membrane cell. An SLM was considered to be stable when it showed a constant flux over time and when there was no water transport. In this case the liquid membrane phase could dissolve a significant amount of water and additionally an osmotic pressure difference $\Delta \Pi$ was present, water transport was observed, and the SLMs were considered to be unstable. A mechanism of membrane failure was proposed in which the presence of an osmotic pressure gradient could lead to the displacement of the organic membrane phase from the support pores by the moving water. To maximize SLM lifetime, systems should be used which are characterized by high organic/water interfacial tensions, a low solubility of water in the 
LM phase, and a low tendency of the support to be wetted by the aqueous phases. These characteristics were, however, not quantified by Danesi et al. but are just qualitative guidelines for obtaining stable SLMs.

Several objections against this osmotic pressure effect can be found in the literature. Neplenbroek et al. $(4,39)$ state that only when the $L M$ phase is removed from the support pores by another primary mechanism, an osmotic water flow might occur. According to Neplenbroek et al., for an osmotic flow of water a continuous water path must be present in the LM phase to create the osmotic pressure difference. However, this objection to the osmotic pressure effect is not correct. To obtain an osmotic pressure gradient, apart from a difference in ionic strength of both aqueous solutions, it is only necessary that the water has a sufficiently high solubility in the LM phase while the ions have not. In that case the membrane is semipermeable to water and an osmotic pressure difference might develop. In the case where a continuous water path is present, an osmotic pressure gradient can develop since both water and ions can be transported. The membrane is no longer semipermeable, and transport of water and ions takes place according to the activity differences of both components between the two phases, and not due to an osmotic pressure difference.

Nevertheless, Neplenbroek et al. showed clearly that in the absence of an osmotic pressure difference by using equal salt concentrations in feed and strip, their SLMs still showed a considerable loss of carrier and solvent $(4,39)$. When an osmotic pressure difference across the membrane was created by an increase in salt concentration in the stripping phase, Neplenbroek et al. showed an increase in stability of the SLM, which is in contradiction with the proposed theory of the osmotic pressure effect. Similar results were obtained by Zha et al. for SLMs for phenol transport $(6,7)$, who also drew the conclusion that the osmotic pressure mechanism was not the cause of SLM degradation in their system. Furthermore, the type of salt used in the aqueous phases had a remarkable influence on carrier removal (39). Since the osmotic pressure is a colligative property and therefore depends upon the number of solute molecules rather than on their kind (35), the osmotic pressure model does not explain the differences. As a conclusion, it appears that an osmotic water flow might be an additional reason of SLM instability, but this depends on the solubility of water in the LM phase. Not all effects can be explained when the osmotic pressure is the only cause of SLM instability.

\section{Shear-Induced Emulsion Formation}

A hypothesis about the instability of supported liquid membranes was proposed by Neplenbroek et al.: emulsion formation induced by lateral 
shear forces $(2,39,50)$. Zha et al. further developed and extended this hypothesis $(6,7,51,52)$. Neplenbroek et al. found a striking similarity between the instability of an SLM and the stability of emulsions formed by droplets of the identical LM phase in the same aqueous environment with the carrier acting as the emulsifier. A relation was found between the removal of the LM phase from the membrane pores as a function of the molecular structure of the carrier, the type of organic solvent, and the formation of oil-in-water emulsions. A similar relation was found for the counterions: the stability of SLMs increased with an increase in the concentration of counterions in the feed and strip phases, while at the same time a decrease of emulsion stability was experimentally observed. The experimental results of Neplenbroek et al. confirmed their emulsion formation hypothesis although the emulsion droplets were never observed directly in the feed solution and no droplet size distributions were given. Similar measurements carried out by Zha et al. on a different system seems to confirm the emulsion formation hypothesis $(6,7)$.

From a thermodynamical point of view, a system will always aim at a surface area as small as possible. Emulsions are therefore per definition thermodynamically unstable. Nevertheless, emulsions can be formed when a sufficiently high amount of energy is supplied to enlarge the surface area. The presence of surface-active species subsequently can stabilize the newly formed surface by creating an energy barrier against reduction of the total surface area of the system. An increase in surface area in SLM systems can be due, for instance, to local deformations of the LM meniscus. Neplenbroek et al. assumed that these deformations could finally lead to the splitting off of emulsion droplets $(2,39,50)$. This is schematically shown in Fig. 3. The local deformations of the LM meniscus can have several origins:

- Kelvin-Helmholtz instabilities: These instabilities occur when two phases move with different velocities parallel to the interface $(53,54)$.

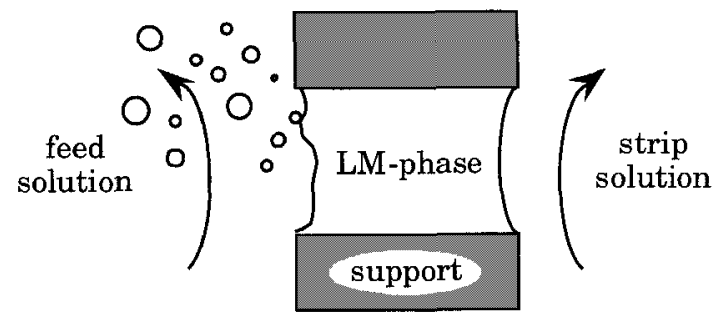

FIG. 3 Schematic drawing illustrating the local deformation of the LM meniscus in the pores of the support resulting in the formation of emulsion droplets. High salt concentration at strip side. low salt concentration at feed side. 
The formation of waves on the water surface due to wind also results from Kelvin-Helmholtz instabilities.

- Vibrations of the membrane: Repeated small deformation of the SLM due to pulsations of the aqueous phases might result in the formation of ripples on the surface of the LM phase (54).

Zha (6) and Gopal (55) mentioned three other hydrodynamic instabilities:

- Instabilities caused by the laminar-turbulent flow transition (Tollmien-Schichting instability).

- Rayleigh-Taylor instabilities which occur when the interface is accelerated perpendicular to its plane and directed from the lighter into the heavier phase.

- The Bernard instability which is due to density differences.

Most likely, Kelvin-Helmholtz instabilities and membrane vibrations are the main causes for deformations of the LM meniscus.

Once the LM meniscus is deformed, emulsion droplets can be formed, e.g., by Marangoni effects (39). These effects create the situation where the meniscus is deformed and becomes unstable, thereby possibly causing droplet shredding and emulsion formation. However, the exact mechanism and influence of hydrodynamic interfacial effects on emulsion formation is a severe problem still not understood (54). Nevertheless, Neplenbroek et al. consider the small size of emulsion droplets removed from their SLMs (between 2 and $140 \mathrm{~nm}$ ) comparable to emulsion droplet sizes in other, Marangoni-effect based systems. That Kelvin-Helmholtz instabilities and membrane vibrations play a role in emulsion formation might be an explanation for decreased SLM stability (higher carrier losses) when flow velocities are increased as was experimentally measured by Neplenbroek et al. (39). The higher the flow velocity, the more meniscus instabilities, and the more probable is emulsion formation. Furthermore, interfacial tension gradients present in SLM systems might exert certain effects on the stability by either promoting or reducing the formation of emulsion droplets, according to Zha et al. $(6,52)$. Although emulsification of the LM phase can explain all observed instability phenomena, it is doubtful whether enough energy can be supplied to the LM interface to cause droplet shredding. Furthermore, the emulsion droplets are never observed directly in the aqueous feed phase.

Summarizing, several mechanisms for the instability of supported liquid membranes are proposed. It is very doubtful whether the pore blocking mechanism is correct. A pressure gradient over the membrane might have an influence on SLM instability but cannot be the major cause since the 
LM liquid lost should have the same composition as the remaining LM phase in the support, which is not the case. This objection also holds for the mechanism of wetting of the LM pores by the aqueous phases. The osmotic pressure might have an effect on the instability of SLMs, but only in case the LM phase can accommodate enough water. Most likely, either the solubility of the LM components in the adjacent aqueous phases or an emulsification of the LM phase due to lateral shear forces is the main mechanism of SLM degradation.

\section{IMPROVEMENT OF SLM STABILITY}

\section{Effect of Membrane Materials and Operating Conditions on Membrane Stability}

In the previous section a number of possible mechanisms for SLM degradation were given. These causes for SLM instability phenomena (most likely the solubility of LM components or an emulsification of the LM phase in adjacent aqueous phases) are related to both membrane materials and operating conditions (33). A proper choice of these factors might improve the lifetime of SLM systems. Different empirical results have been obtained, and these will be discussed first.

Considering membrane materials, we can distinguish between the solvent for the carrier, the carrier itself, and the support (18). It is obvious that the organic solvent used has a large influence on membrane stability. From several studies it can be concluded that in order to raise the lifetime of SLMs, the organic solvent should have a low solubility in water (14, 20,56 ), and water should possess a low solubility in the organic solvent $(12,20,24,37)$. The solvent should furthermore have a high interfacial tension between the solvent and the water phases $(3,5,12,20,26,39)$ and a high boiling point (37).

The carrier lipophilicity and surface activity, together with its solubility in the membrane solvent, are important for the stability of a SLM. The more surface active the carrier is, the less stable is the membrane (25, $39)$. By attaching carriers onto a polymer $(57,58)$ or when the carrier is covalently linked onto (long-chain) aliphatic chains $(37,59)$, the partition of the carrier toward the aqueous phases can be decreased. Disadvantages of these techniques are the decrease of flux due to the increase in LMphase viscosity and the limited solubility of modified carriers in the membrane solvent. Visser succeeded in binding the carrier covalently to the membrane solvent and improved the compatibility of several carriers with the solvent in this way (33). Stability experiments with these solventbound carriers were promising, although at higher carrier concentrations the flux was low. 
The type of support used influences SLM stability in several ways. From the Laplace equation (Eq. 1 in this paper), one can conclude that SLMs using supports with a lower pore size are in general more stable than those with a large pore size. In accordance with this, Danesi et al. advised the use of supports with a small pore size (12), although the surface porosity should be high enough to obtain a reasonable flux. Zha et al. recommended the use of supports with a morphology having a less connected network and sharp pore edges (34). In the case of a connected network, once LM loss has started, the impregnating liquid in the neighboring branch pores will be dragged out of the support continuously by the aqueous phase due to viscous forces. This should result in more passages for the aqueous phases. However, it is not clear why the aqueous phase would pass through the bigger pores, and whether these viscous forces are strong enough. Contrary to Zha's advice, Neplenbroek et al. found that Accurel supports lead to substantially more stable SLMs than Celgard due to their larger thickness and interconnected pore structure $(2,39)$. Another important support characteristic is the wettability of the membrane. Only when the support is wetted sufficiently by the organic phase can absorption of the aqueous phase into the SLM be minimized $(5,12)$. According to Takeuchi et al., the organic LM phase should have a surface tension smaller than the "critical" surface tension of the support (5). Although hydrophilic microfiltration membranes can be used as a support $(60,61)$, inferior transport properties are obtained due to poor wettability and immobilization of the impregnating liquid. Better results with hydrophilic supports were obtained when the LM phase was impregnated in the form of an oil-in-water emulsion $(60,61)$, but this does not seem logical and the system used is not well described. In general, however, hydrophobic supports are better from a stability point of view.

Membrane thickness, stirring rate or pumping velocity, carrier concentration, aqueous solute concentration, and operating temperature are operating conditions that influence membrane stability (26). In general, the higher the membrane thickness, the more stable the SLM simply because the support contains more LM phase and therefore it will take longer before the SLM breaks down (62). However, feed and strip will be polluted with more LM phase, which might be unacceptable for several (pharmaceutical or environmental) applications. Furthermore, Chiarizia states that a larger thickness makes water bridging between feed and strip phases through membrane pores, lacking some organic phase, practically impossible (25). Examples are the higher stability of SLMs with Accurel as a support compared to the thinner Celgard membranes (39) or the improved stability when hollow fibers which have a larger thickness than flat-sheet supports $(25,63)$. Teramoto et al. showed that a constant copper flux could be maintained for 30 hours when a Teflon Gore-Tex TA-002 hollow 
fiber (thickness $400 \mu \mathrm{m}$ ) was used as the support. Under the same conditions a thinner polypropylene KPF-400 fiber $(33 \mu \mathrm{m})$ showed a flux decrease immediately after the experiment was started (64).

Not much data were found in the literature on the influence of stirring rate on SLM stability. However, Neplenbroek et al. observed an increase in both carrier and solvent losses for flat sheet SLMs when the pumping velocity was increased (39). It might be expected that an increase in stirring rate would have the same effect on stability. This was confirmed by Zha et al. $(6,7,51)$. Izatt et al. concluded from their measurements on hollowfiber SLMs that the pumping velocity has the same effect on flux as the stirring rate in flat-sheet liquid membranes (19). Furthermore, an increase in pumping velocity when hollow fibers are used as a support increases the pressure drop over the membrane. This may result in a larger loss of LM phase when the transmembrane pressure difference $\Delta P$ is larger than the minimum transmembrane pressure required to displace the impregnated phase out of the most susceptible pores. In the case where the outside and inside hydraulic pressures were balanced in a hollow-fiber SLM, Danesi et al. observed a constant flux over a period longer than 2 months (3). Takigawa designed a special spiral-type membrane module $(60,61)$. Strip and feed phases flowed countercurrently through machined channels in two half-cell faceplates that were in a spiral, mirror-image pattern with respect to each other. In this way the pressure difference between feed and strip could be minimized when the viscosities of the two phases did not differ much. Consequently, the membrane was much more stable than when other cell configurations were used.

In case the carrier concentration reaches the saturation limit, it might form solid or gelatinous precipitates in the membrane pores as was observed by Chiarizia (25). Chiarizia thought this precipitation to be a convenient way for enhancing the stability of the membrane by preventing emulsion formation with the aqueous phase and by acting as a barrier against water bridging in semidevoid pores. However, the exact mechanism of this stability improvement by carrier precipitation is not elucidated. In the case where the carrier is surface-active, a higher carrier concentration will decrease the interfacial tension of the organic phase, which will in general lead to less stable membranes.

Neplenbroek et al. observed a decrease in SLM lifetime when the solute concentration in either feed or strip was decreased $(4,39,50)$. Partition of crown ethers toward the aqueous phases was increased when the $\mathrm{pH}$ was lowered to values below 10 . This leaching of carrier decreased membrane stability $(58)$.

Finally, the operating temperature might be of importance in determining membrane stability. Saito found the lifetime of SLMs for $\mathrm{Zn}^{2+}$ to be 60,50 , and 20 hours when the temperature was 25,40 , and $60^{\circ} \mathrm{C}$, respec- 
tively (65). This was explained by an increased solubility of both membrane solvent and carrier in the aqueous phases at higher temperatures. It might also be expected that the water solubility in the membrane phase increases at elevated temperatures. In general, membrane lifetime is usually lower when temperature increases.

It is clear from the above-mentioned effects of membrane materials and operating conditions on membrane stability that they mainly influence the solubility of LM components into adjacent aqueous phases and the tendency of the LM phase to form emulsions with the aqueous feed or strip. The experimental results are therefore in favor of these two mechanisms.

\section{Methods of SLM-Lifetime Enhancement}

Once an SLM system (support, carrier, organic solvent, and aqueous phases) is chosen or fixed by the situation, there are several other methods, which can be found in literature, to enhance the stability. In this section a number of them will be discussed in more detail.

\section{Reimpregnation of the Support}

One of the methods described in literature is reimpregnation of the support with the LM phase. Babcock et al. reloaded both flat-sheet and hollow-fiber supports with fresh LM solution after they were decayed, and their results showed a restoration of the flux after reimpregnation (43). Several other authors used the regeneration technique for "stabilizing" SLMs (9, 14, 16, 49, 66). Teramoto and Tanimoto regenerated degraded hollow fiber liquid membranes by simply reimpregnating them with the original LM phase which was forced to flow at the lumen side of the membrane for a few minutes instead of the aqueous acid solution (64). Copper flux recovered immediately to the initial value. An alternative proposed by the authors for preventing the flux decrease was to add a small amount of LM phase to the strip solution. The organic solution will flow through the inside of the fiber and refill the vacant pores continuously with fresh LM phase. In this way the pores are always filled with the LM phase and the flux will be constant for a long period of time. No experimental data on this alternative method were presented. This idea was also used by Takahashi and Takeuchi (8). In a special LM module with two channels on both sides of the impregnated support, the membrane solution was forced to flow with the strip solution to stabilize the SLM. By keeping the pressure in the feed channels higher than in the strip channel, leakage of membrane solution to the feed was avoided. Disadvantages of these techniques are the loss of extractant, which is as severe as in ordinary 
solvent-solvent extraction, and the necessity of an additional separation step to remove the membrane solution from the strip.

To avoid the additional separation step, a continuous impregnation of the membrane is possible. Such continuous impregnation methods are mainly applied for hollow-fiber modules and can be found in different configurations. Nakano et al. designed a vertical hollow-fiber module containing one single fiber with a certain amount of liquid membrane phase at the bottom. The membrane liquid in the "pool" at the bottom was soaked into the pores of the support and moved upward through the porous support network by capillary and buoyant forces (13). The same research group also designed a module on a larger scale based on the same idea (15). Chiarizia et al. also used a vertical membrane module, but in their case the LM-phase reservoir was placed on top of the module (66). The organic phase was soaked into the membrane pores by gravitational and capillary forces. Tanikagi et al. developed a horizontal liquid membrane module for continuous regeneration (14) in which the liquid membrane phase was forced to refill the pores by means of a pressure difference. One example of continuous regeneration of flat-sheet SLMs is known. Fujinawa et al. reported that by laminating nonwoven polypropylene fibers containing membrane liquid to a Teflon film, the SLM was recharged continuously (67). However, the reimpregnation only lasted a limited time.

Continuous regeneration of liquid membranes works well, but feed and/ or strip solutions are still polluted with the membrane liquid. Therefore, according to our opinion, these membranes are not "stable." Only the effects of LM loss are cured, but the problem of instability itself is not tackled. Other disadvantages are the necessity to fill up the membrane liquid, the complex modules, and the procedures required.

\section{Sandwich SLMS}

Zhu et al. reported a great prolongation of SLM lifetime when a suitable sandwich SLM was used in operation (47). By interposing an SLM between two pieces of hydrophilic lens paper, a stagnant aqueous layer was built up in the paper. According to Zhu et al., in this way no micelles of carrier and water were formed at the interface and introduced into the SLM which would decrease the permeability of copper. Experimental results showed a "longer membrane lifetime" at almost equal permeabilities, but this lifetime is not mentioned. Another objection against their idea is that the components necessary for micelle or aggregate formation (water and carrier) are still present. Whether the aggregates are formed or not depends on the concentration of water and carrier and the thermo- 
dynamic ability to form micelles. This has nothing to do with the presence of the lens paper. A similar system was used by Saito, who sandwiched the SLM between two hydrophilic dialysis membranes $(15 \mu \mathrm{m}$ thickness each) to prevent the loss of membrane solvent and carrier (65). The lifetime of the sandwiched SLM was higher than that of the ordinary SLM, but still there were stability problems. Permeation velocity was decreased to one-fifth of the value for a single SLM. Concluding, the idea of using sandwich SLMs is not bad, but no good experimental proofs have been reported.

\section{Gelation of SLMS}

The idea of using gelled membranes was first proposed by Bloch et al. in the late sixties (38). Polyvinyl chloride, PVC, was plasticized with several phosphate esters which could act as extractants for uranium. These socalled solvent membranes had a lifetime which was insufficient due to a washout of extractant and subsequent impermeability of the PVC films.

Babcock et al. tried to increase the viscosity of an organic solution in a polymeric support with several polymers (44). In this way the mechanical strength of the liquid membrane should increase and separation or displacement by aqueous droplets should be prevented (see their pore blocking mechanism described before). Two polymers were studied: polyisoprene and polyvinyl chloride (PVC). Polyisoprene was added to the carrier solution, after which the supports were impregnated with the polymer/ LM-phase mixture. No improvement in membrane lifetime was observed. When PVC was applied as polymer, it was dissolved in THF and a carrier, LIX 54, was added. After impregnation of the support with this mixture and subsequent evaporation of THF, a gel was formed. A long-term copper permeation test over a period of 28 days revealed considerable stability improvement compared to other membranes without PVC. Nevertheless, the absolute value of the initial flux was somewhat lower.

Based on their emulsion formation hypothesis for membrane degradation, Neplenbroek et al. used gelation of the LM phase to stabilize SLMs $(2,10,50)$. By gelling the membrane liquid, its macroscopic viscosity increases and the resistance against liquid displacement out of the support will be enhanced. By effectively preventing the LM meniscus from deforming, emulsion formation is prevented. As a consequence, the SLM will be more stable, provided that emulsion formation is the main reason for SLM instability. The stabilization of the liquid membrane by gelation with PVC was carried out in two different ways as shown in Fig. 4. First, the whole LM phase was gelled inside the pores of the support (Fig. 4a). Mechanical stability was increased as shown by liquid displacement ex- 


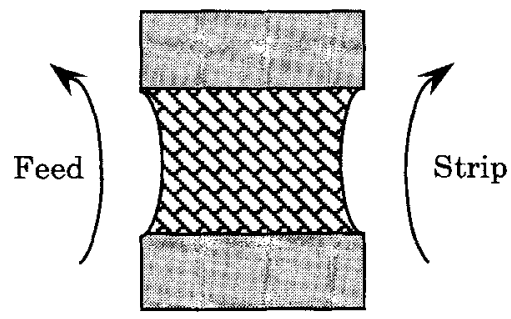

(a)

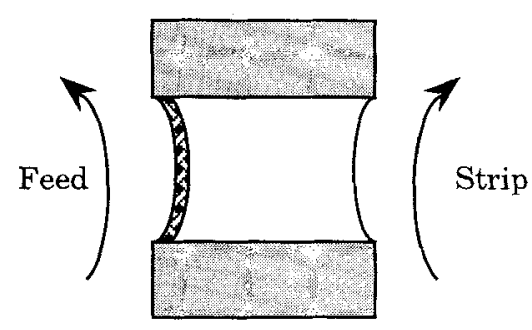

(b)

FIG. 4 Schematic drawing illustrating the stabilization of SLMs by gelation. (a) Homogenous gel network in the support pores. (b) Thin dense gel layer at feed side.

periments, while in the meantime LM loss was less. At higher PVC concentrations, however, the initial nitrate flux was decreased. Neplenbroek et al. assumed that this was due to the increase in tortuosity factor when the LM phase was gelated $(2,10,50)$.

Better results were obtained when PVC was applied as a thin layer $(<2$ $\mu \mathrm{m})$ on the feed side of the support and crosslinked after preparation (Fig. 4b). In this way the resistance toward transport was minimized. Furthermore, emulsion formation could be suppressed more effectively: the polymer concentration could be higher, and as a result the deformation of the LM meniscus was prevented more effectively. Their results were very astonishing and promising. The best membranes showed no flux decrease after $\mathbf{8 0}$ hours under circumstances which enhanced significantly the degradation of the SLM, without a reduction in initial flux compared to SLMs without a gel layer. A membrane lifetime far over 1 year under normal circumstances was predicted by the authors $(2,10,50)$. The major disadvantage of this technique is the bad reproducibility. Furthermore, the coating of the membrane with the gel layer using their technique, i.e., spreading the gel with a tissue as smoothly as possible over the membrane surface, seems not to be suitable for large-scale applications and the coating of hollow fibers. Based on Neplenbroek's promising results, Bromberg et al. (68) and Levin et al. (69) also homogeneously gelated their SLMs. Both authors, however, give no data on liquid membrane stability.

Concluding, reimpregnation of the support with fresh LM phase is not a solution for the stability problem. There is still a significant loss of $\mathrm{LM}$ phase, and the aqueous phases are polluted with the membrane liquid, which is certainly not desirable. The concept of using sandwich SLMs looks promising but has to be worked out in more detail. Finally, gelation 
of the LM phase works well to prevent emulsification of the membrane liquid into the aqueous phases or to minimize displacement of LM liquid from the support pores by a pressure difference over the membrane. However, the industrial applicability of gelation is limited.

\section{NEW LIQUID MEMBRANE CONFIGURATIONS}

Some authors tried to avoid the instability problems inherent to SLMs by developing new liquid membrane configurations. These configurations have all in common that they are a combination of supported liquid membranes and bulk liquid membranes. The membrane phase contains a carrier which binds with one of the components in the feed and transports it across the membrane to the receiving phase. In most cases the authors claimed that these configurations combined the advantages of liquid membranes with an improved stability and avoidance of the disadvantages of extraction and absorption. In this section these new liquid membrane configurations will be discussed in more detail.

Two types of film pertractors are drawn in Fig. 5. The creeping film pertractor (Fig. 5a) was developed by Boyadzhiev (70-72) and further investigated by Lazarova et al. $(73,74)$. In contradiction to the SLM

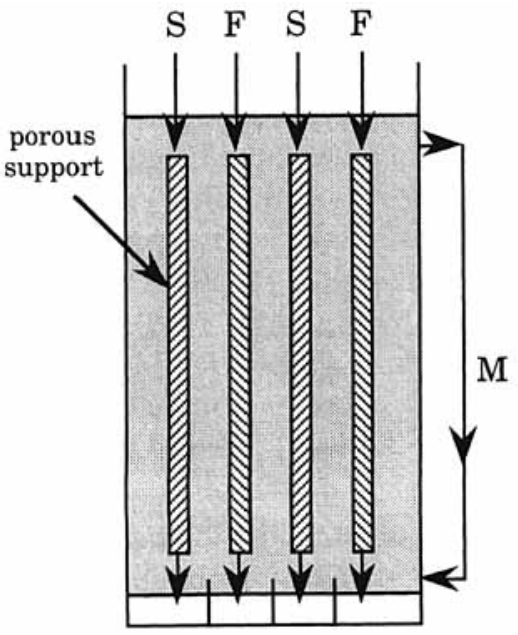

(a)

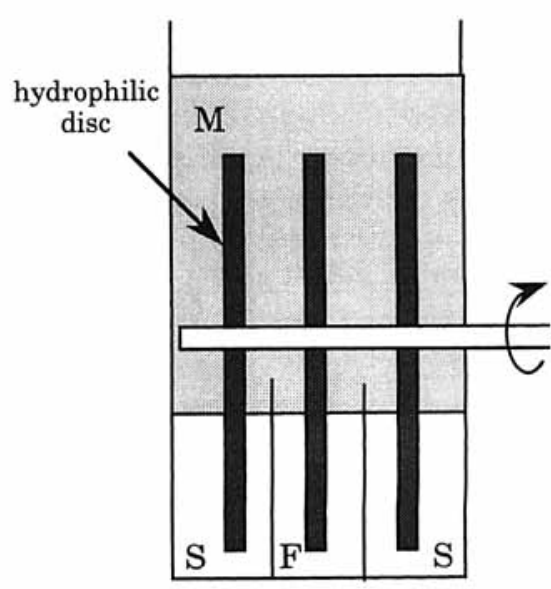

(b)

FIG. 5 Schematic drawing illustrating the operating principle of two types of film pertractors. (a) Creeping film pertractor. (b) Rotating film pertractor. $\mathrm{M}=$ membrane phase, $\mathrm{S}=$ stripping solution, $F=$ feed solution. Adapted from Schlosser (28). 
process, besides the feed and strip solutions the organic LM phase is also in motion. Feed and strip flow down the vertical hydrophilic porous supports, placed in an alternating sequence. The whole pertractor volume is filled with the organic phase which is circulated in a cocurrent or countercurrent mode. Construction and operation of this pertractor is claimed to be simple, inexpensive, flexible, and easy to scale up. Another advantage would be that the velocities of the three phases could be controlled independently, while the vertical flow, the immiscibility, and the density differences ensure stable interfaces (18). Continuous operation times of more than 3000 hours have been reported by Boyadzhiev without any efficiency loss or process deterioration (72). However, Boyadzhiev did not give data on pollution of the feed and strip phases with the membrane liquid. Fraser et al. modified the creeping film pertractor to make it suitable for use with strongly alkaline stripping solutions (18).

Another variation on the film pertractor idea was the rotating film pertractor (Fig. 5b) developed by Schlosser et al. (28) and also used by Boyadzhiev et al. $(75,76)$. Hydrophilic disks were mounted on a horizontal shaft. The lower parts of the disks were dipped in compartments alternately filled with strip and feed solutions. On these parts of the disks, due to rotation, films of water were formed which were immersed in the membrane phase where extraction and stripping took place. According to some studies, the rotating film pertractor offered a stable operation without side effects under both continuous and batch regimes (75). No data on the lifetime were presented, however, and here also feed and strip might become contaminated with the membrane solution.

Two other variations on the pertractor idea are shown in Fig. 6. The flowing liquid membrane (FLM) configuration was first proposed by Teramoto et al. (77-79). In this type of liquid membrane the LM phase flows in thin channels between two hydrophobic microfiltration membranes. These microfiltration membranes separate the LM phase from feed and strip and, according to the authors, form in this way a stable liquid membrane. The flowing liquid membrane is shown schematically in Fig. 6(a). First, a spiral-type module was designed for the recovery of chromium and zinc (77). Although this type of module was tested for only 100 hours, it was claimed to have a high stability. With flat-sheet PTFE microfiltration membranes as support, the flowing liquid membrane was applied for the separation of ethylene from ethane and benzene from cyclohexane using silver nitrate as carrier $(78,79)$. Comparison of the flowing liquid membrane results with those of ordinary SLMs for ethylene/ethane separation revealed a higher stability for the FLM. The stability of the flowing liquid membrane for benzene transport was 11 days without a flux decrease, but here no comparison was made with supported liquid mem- 


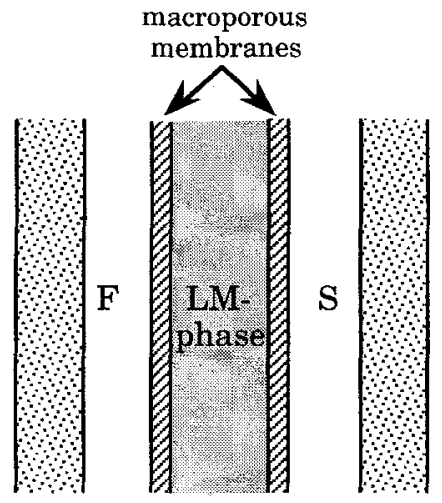

(a)

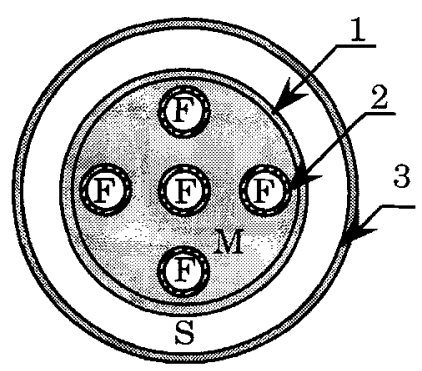

(b)

FIG. 6 (a) Flowing liquid membrane. $F=$ feed channel, $S=$ strip channel. (b) Top view of a hollow-fibers-in-tube type pertractor. $\mathrm{F}=$ feed solution, $\mathrm{S}=$ stripping solution, $\mathrm{M}=$ liquid membrane phase. 1 = tubular wall (hydrophilic polysulfone), 2 = hollow fiber, $3=$ glass wall. Adapted from Teramoto et al. (77) and Schlosser et al. (80).

branes. Furthermore, leakage between aqueous and organic solutions in FLMs frequently happens (6), which is undesirable.

Schlosser and Rothová recently published results of a new type of hollow-fiber pertractor (see Fig. 6b) which is, in fact, also a flowing liquid membrane since all three liquids are in motion and the membrane phase is not flowing through a porous support as is the case in creeping film pertractors $(80)$. The feed is flowing through hydrophobic hollow fibers, where it is extracted by the LM phase. The stripping reaction takes place at the hydrophilic polysulfone tube. By pulsating the membrane phase, mass transfer is enhanced substantially. No data on membrane lifetime are given, nor were data given on loss of membrane liquid to the aqueous phases.

The hollow-fiber pertractor of Schlosser and Rothová can also be regarded as a variation on the contained liquid membrane. The idea of contained liquid membranes (CLMs) was developed in the late eighties by the Sirkar group (17, 81-84). In a CLM, two sets of hollow fibers are present (schematically drawn in Fig. 7). The hollow fibers are well mixed throughout the permeator, but they are separated at the end. The fibers can be either hydrophilic or hydrophobic. The aqueous feed and strip solutions flow through the lumen side of the fibers and, depending on the hydrophilicity of the fibers, fill the pores of the fiber (in the hydrophilic 


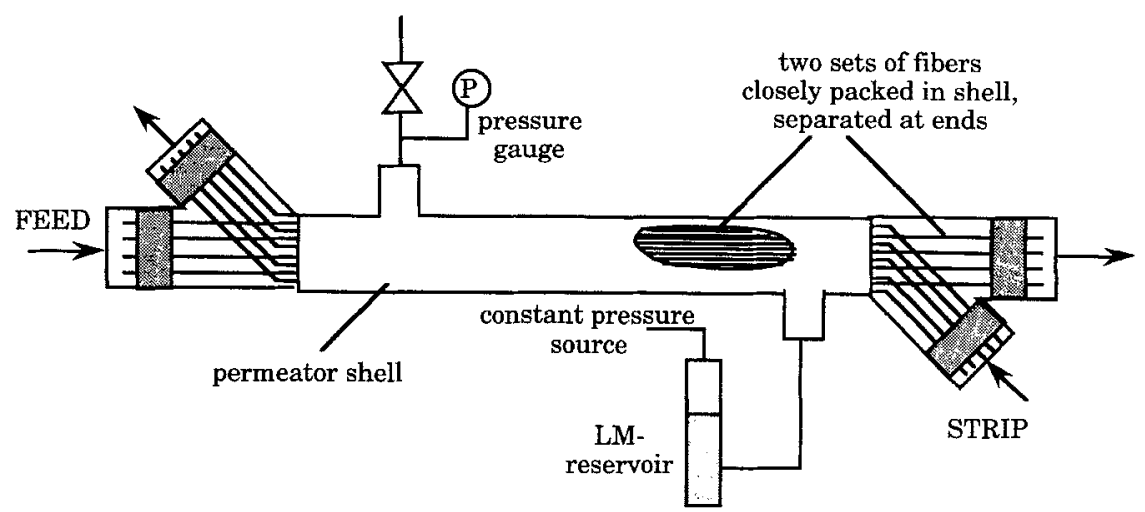

(a)

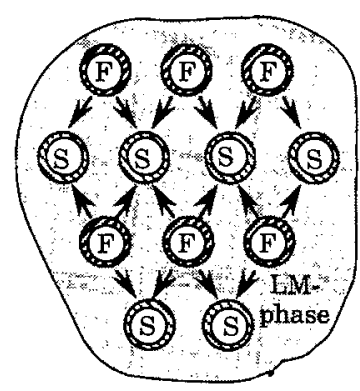

(b)

FIG. 7 Schematic drawing of a hollow fiber contained liquid membrane. (a) Side view of the permeator. (b) Internal structure and arrangement of the fibers. Adapted from Sengupta et al. $(81,82)$.

case) or the fibers are wetted by the organic membrane phase (when the fibers are hydrophobic). It is also possible to use organic solutions as feed and strip phases. In that case an aqueous or polar organic solution is applied as the liquid membrane phase. The membrane phase contains a selective complexing agent which binds at the interface in one set of fibers with one of the components of the feed solution. The complex diffuses across the (organic) liquid membrane and dissociates in the other set of fibers where the component transported is released to the strip solution.

Hollow fibers containing liquid membranes have been used for different applications. Sengupta et al. transferred phenol or acetic acid with hydrophobic and hydrophilic hollow fiber CLMs (HFCLMs) $(81,82)$. Citric acid 
was successfully separated from aqueous solutions by Basu et al. (83), while the recovery of pharmaceutical products by HFCLMs was studied by the same authors (17). In all cases an elimination of stability problems as encountered in supported liquid membranes is claimed. Stabilities up to 60 days are reported (83). Nevertheless, these long-term experiments are somewhat misleading since no explicit attention is paid to the fact that the contained liquid membranes all use a membrane reservoir to refill the permeator with fresh LM liquid which is lost to the feed and strip phases.

This loss of LM phase is also a problem for the flowing liquid membranes and the film pertractors. Sometimes even the use of an aqueous-organic separator is required (85). Moreover, the processes are more complicated than SLMs, while the total resistance to permeation of solute from feed to strip is increased. Finally, these membrane configurations in general need a much larger amount of LM phase than supported liquid membranes, which might be disadvantageous when expensive extractants are used.

A relatively new variation on liquid membranes is the so-called electrostatic pseudo liquid membrane (ESPLIM) developed in China by Gu et al. $(22,86,87)$. The process is a combination of an electrostatic technique with the principle of a liquid membrane. The porous membrane in SLMs is replaced by a baffle which separates feed and stripping cell. Inside the cell, within the baffle plates, an oil layer containing the carrier is present which is rather stagnant and acts as the liquid membrane. When an alternating current (ac) high-voltage electrostatic field is applied simultaneously to both cells, the feed and strip solutions added to the extraction and stripping cell, respectively, are dispersed into numerous droplets in the continuous organic phase. The complex formed in the extraction cell diffuses through the baffle plate into the stripping cell where the product is released. In general, fluxes are of the order of $10^{-7}$ to $10^{-8}$ $\mathrm{mol} \cdot \mathrm{cm}^{-2} \cdot \mathrm{s}^{-1}$, two magnitudes of order higher than in most SLMs. The authors claim the technique to be more stable than supported liquid membranes (22), but do not show any data on long-term stability. Another disadvantage, again, is the complex operation of the process.

Finally, Kedem and Bromberg describe the use of ion-exchange membranes in extraction processes (88). Ion-exchange membranes were used to separate aqueous feed solution from the organic extraction phase as is schematically shown in Fig. 8. Three different techniques were used: a two-chamber cell in which feed and extractant solution were separated by the ion-exchange membrane (Fig. 8a), a three-chamber cell with an extra ion-exchange membrane and a "strip" solution (Fig. 8b), and a variation on the first technique in which aqueous feed and organic extractant solution were flowing parallel to the membrane. In the case of copper 


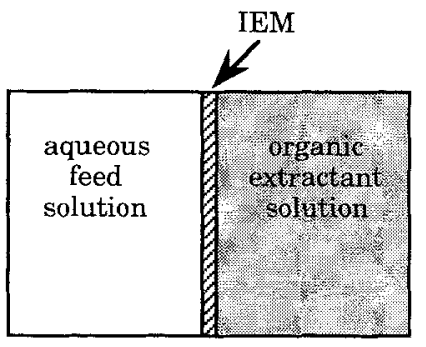

(a)

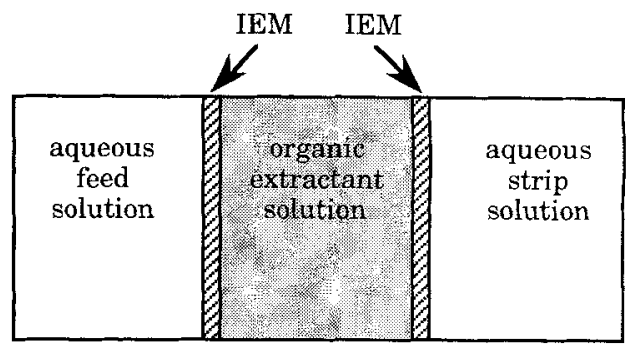

(b)

FIG. 8 The use of ion-exchange membranes in extraction processes in a two-chamber (a) or a three-chamber cell. (b) IEM $=$ ion-exchange membrane.

transport, a cation-exchange membrane separated the different solutions, and the removal of acid was conducted using anion-exchange membranes. According to the authors, the ion-exchange membranes could prevent the loss of extractant to the aqueous solutions with a solute flux similar to that of ordinary supported liquid membranes. A similar system was described recently by Isono et al. in which extraction of acids into an organic solution was combined with electrostatic rejection effects using cation-exchange membranes (89). However, this technique is new and much research is still needed on the transport mechanism and stability.

\section{CONCLUSIONS}

Different possible causes of SLM instability were discussed. Only two mechanisms for SLM instability seem to be of major importance and can explain the loss of membrane solvent and carrier in different ratios: the solubility of the LM components in the adjacent feed or strip solutions and an emulsification of the LM phase due to lateral shear forces. A review is given on methods for SLM lifetime improvements. A careful choice of membrane conditions and materials is important and may enhance membrane stability by its influence on solubility and emulsification of LMphase components into adjacent aqueous solutions. Once the system is fixed, several suggestions for lifetime improvement can be found in the literature. Gelation of the LM phase to prevent loss by emulsification is especially very encouraging but difficult to apply on an industrial scale. New liquid membrane configurations are promising, but in general, operation of these liquid membranes is much more difficult than with ordinary SLMs. 


\section{REFERENCES}

1. D. Barnes, G. Marshall, and J. van Staden, "Rapid Optimization of Chemical Parameters Affecting Supported Liquid Membranes," Sep. Sci. Technol., 30(5), 751-776 (1995).

2. A. M. Neplenbroek, "Stability of Supported Liquid Membranes," Ph.D. Thesis, University of Twente, 1989.

3. P. Danesi, "Separation of Metal Species by Supported Liquid Membranes," Sep. Sci. Technol., 19(11\&12), 857-894 (1984-85).

4. A. M. Neplenbroek, D. Bargeman, and C. A. Smolders, "Supported Liquid Membranes: Instability Effects," J. Membr. Sci., 67, 121-132 (1992).

5. H. Takeuchi, K. Takahashi, and W. Goto, "Some Observations on the Stability of Supported Liquid Membranes," Ibid., 34, 19-31 (1987).

6. F.-F. Zha, "Stability and Applications of Supported Liquid Membranes," Ph.D. Thesis, University of New South Wales, 1993.

7. F.-F. Zha, A. G. Fane, and C. J. D. Fell, "Instability Mechanisms of Supported Liquid Membranes in Phenol Transport Model," J. Membr. Sci.. 107, 59-74 (1995).

8. K. Takahashi and H. Takeuchi, "Transport of Copper through a Supported Liquid Membrane," J. Chem. Eng. Jpn., 18(3), 205-211 (1985).

9. O. Loiacono, E. Drioli, and R. Molinari, "Metal Ion Separation and Concentration with Supported Liquid Membranes," J. Membr. Sci., 28, 123-138 (1986).

10. A. M. Neplenbroek, D. Bargeman, and C. A. Smolders, "Supported Liquid Membranes: Stabilization by Gelation," Ibid, 67, 149-165 (1992).

11. A. Urtiaga, M. Ortiz, E. Salazar, and J. Irabien, "Supported Liquid Membranes for the Separation-Concentration of Phenol. 1. Viability and Mass Transfer Evaluation," Ind. Eng. Chem. Res., 31, 877-886 (1992).

12. P. Danesi, L. Reichley-Yinger, and P. Rickert, "Lifetime of Supported Liquid Membranes: The Influence of Interfacial Properties, Chemical Composition and Water Transport on the Long Term Stability of the Membranes," J. Membr. Sci., 31, 117-145 (1987).

13. M. Nakano, K. Takahashi, and H. Takeuchi, "A Method for Continuous Regeneration of Supported Liquid Membranes," J. Chem. Eng. Jpn., 20(3), 326-328 (1987).

14. M. Tanigaki, M. Ueda, and W. Eguchi, "Facilitated Transport of Zinc Chloride through Hollow Fiber Supported Liquid Membrane. Part 2. Membrane Stability," Sep. Sci. Technol., 23(10\&11), 1161-1169 (1988).

15. H. Takeuchi, K. Takahashi, and M. Nakano, "Separation of Heavy Metals from Aqueous Solutions by Hollow-Fiber Type Supported Liquid Membranes in a Continuous Regeneration Mode," Water Treat., 5, 222-236 (1990).

16. R. Molinary, L. De Bartolo, and E. Drioli, "Coupled Transport of Animoacids Through a Supported Liquid Membrane. I. Experimental Optimalization," J. Membr. Sci., 73, 203-215 (1992).

17. R. Basu and K. Sirkar, "Pharmaceutical Product Recovery Using a Hollow Fiber Contained Liquid Membrane: A Case Study," J. Membr. Sci., 75, 131-149 (1992).

18. B. Fraser, M. Pritzker, and R. Legge, "Development of Liquid Membrane Pertraction for the Removal and Recovery of Chromium from Aqueous Effluents," Sep. Sci. Technol., 29(8), 2097-2116 (1994).

19. R. Izatt, D. Koper, R. Bruening, and J. Lamb, "Macrocycle-Mediated Cation Transport Using Hollow Fiber Supported Liquid Membranes," J. Membr. Sci., 45, 73-84 (1989). 
20. P. Deblay, S. Delepine, M. Minier, and H. Renon, "Selection of Organic Phases for Optimal Stability and Efficiency of Flat-Sheet Supported Liquid Membranes," Sep. Sci. Technol., 26(1), 97-116 (1991).

21. M. Matsumura and H. Kataoka, "Separation of Dilute Butanol and Acetone Solutions by Pervaporation through Liquid Membranes," Biotechnol. Bioeng., 30, 887-895 (1987).

22. Z. Gu, "Electrostatic Pseudo-Liquid-Membrane" in Membrane Handbook (W. Ho and K. Sirkar, Eds.), Van Nostrand Reinhold, New York, 1987, Chap. 44, pp. 867-884.

23. C. Fabiani, M. Merigiola, S. Scibona, and A. Casagnola, "Degradation of Supported Liquid Membranes under an Osmotic Pressure Gradient," J. Membr. Sci., 30, 97-104 (1987).

24. J. Dozol, J. Casas, and A. Sastre, "Stability of Flat Sheet Supported Liquid Membranes in the Transport of Radionuclides from Reprocessing Concentrate Solutions," $J$. Membr. Sci., 82, 237-246 (1993).

25. R. Chiarizia, "Stability of Supported Liquid Membranes Containing Long-Chain Aliphatic Amines as Carrier," Ibid., 55, 65-77 (1991).

26. H. Takeuchi and M. Nakano, "Progressive Wetting of Supported Liquid Membranes by Aqueous Solutions," Ibid., 42, 183-188 (1989).

27. R. D. Noble and J. D. Way, "Liquid Membrane Technology. An Overview," in Liquid Membranes: Theory and Applications, ACS Symposium Series 347, 1987, Chap. 1, pp. 1-26.

28. S. Schlosser, "Liquid Membranes: Theory and Practice," in Lecture Book, ESMST Summer School "Advances in Membrane Phenomena and Processes," Gdansk, Poland, 1988, pp. 163-183.

29. A. Eyal and E. Bressler, "Mini Review. Industrial Separation of Carboxylic and Amino Acids by Liquid Membranes: Applicability, Process Considerations, and Potential Advantages," Biotechnol. Bioeng., 41, 287-295 (1993).

30. R. Noble, C. Koval, and J. Pellegrino, "Facilitated Transport Membrane Systems," Chem. Eng. Prog., 85, 58-70 (1989).

31. R. Baker and 1. Blume, "Coupled Transport Membranes," in Handbook of Industrial Membrane Technology, Noyes, New Jersey, 1990, Chap. 9, pp. 511-158.

32. J. Schultz, "Carrier-Mediated Transport," in Synthetic Membranes: Science, Engineering and Applications, NATO ASI Series, C181 (P. Bungay et al., Eds.), Reidel, Dordrecht, 1986, pp. 523-566.

33. H. Visser, "Supported Liquid Membranes with Improved Stability: Kinetics and Mechanism of Carrier Mediated Salt Transport," Ph.D. Thesis, University of Twente, 1994.

34. F. Zha, A. Fane, C. Fell, and R. Schofield, "Critical Displacement Pressure of a Supported Liquid Membrane," J. Membr. Sci., 75, 69-80 (1992).

35. J. Lyklema, Fundamentals of Interface and Colloid Science, Volume I: Fundamentals, Academic Press, London, 1991.

36. I. M. Wienk, B. Folkers, Th. van den Boomgaard, and C. A. Smolders, "Critical Factors in the Determination of the Pore Size Distribution of Ultrafiltration Membranes Using the Liquid Displacement Method," Sep. Sci. Technol., 29(11), 1433-1440 (1994).

37. J. D. Lamb, R. Bruening, R. Izatt, Y. Hirashima, P.-K. Tse, and J. J. Christenen, "Characterization of a Supported Liquid Membrane for Macrocycle-Mediated Selective Cation Transport," J. Membr. Sci., 37, 13-26 (1988).

38. R. Bloch, A. Finkelstein, O. Kedem, and D. Vofsi, "Metal-Ion Separation by Dialysis through Solvent Membranes," Ind. Eng. Chem., Process Des. Dev., 6(2), 231-237 (1967).

39. A. M. Neplenbroek, D. Bargeman, and C. A. Smolders, "Mechanism of Supported 
Liquid Membrane Degradation: Emulsion Formation," J. Membr. Sci., 67, 133-48 (1992).

40. A. Franken, J. Nolten, M. Mulder, D. Bargeman, and C. Smolders, "Wetting Criteria for the Applicability of Membrane Distillation," Ibid., 33, 315-328 (1987).

41. S. Belfer, S. Binman, Y. Lati, and S. Zolotov, "Immobilized Extractants: Selective Transport of Magnesium and Calcium from a Mixed Chloride Solution via a Hollow Fiber Module," J. Appl. Polym. Sci., 40, 2073-2085 (1990).

42. R. Chiarizia, "Application of Supported Liquid Membranes for Removal of Nitrate, Technetium(VII) and Chromium(VI) from Groundwater,' J. Membr. Sci., 55, 39-64 (1991).

43. W. C. Babcock, R. W. Baker, D. J. Kelly, W. Kleiber, and H. K. Lonsdale, "Coupled Transport Membranes for Metal Separations," NTIS Rep., pp. 59-70 (August 1979).

44. W. C. Babcock, R. W. Baker, J. Brooke, D. Kelly, E. LaChapelle, and H. K. Lonsdale, Coupled Transport Membranes for Metal Recovery-Phase II, Final Report, National Science Foundation, August 31, 1980.

45. J. Overbeek, "Microemulsions, A Field at the Border between Lyophobic and Lyophilic Colloids," Faraday Disc., 65, 7-19 (1978).

46. D. Langevin, "Low Interfacial Tensions in Microemulsion Systems," in Microemulsions: Structure and Dynamics (S. Friberg and P. Bothorel, Eds.), CRC Press, Boca Raton, FL, 1987, Chap. 7, pp. 173-196.

47. G. Zhu and B. Li, "A Study of Water Uptake in Supported Liquid Membranes," Water Treat., 5, 150-156 (1990).

48. M. Mulder, Basic Principles of Membrane Technology, Kluwer, Dordrecht, 1991.

49. R. Molinary, E. Drioli, and G. Pantano, "Stability and Effect of Diluents in Supported Liquid Membranes for Cr(III), Cr(IV), and Cd(II) Recovery," Sep. Sci. Technol., 24(12\&13), 1015-1032 (1989).

50. A. M. Neplenbroek, D. Bargeman, and C. A. Smolders, "The Stability of Supported Liquid Membranes," Desalination, 79, 303-312 (1990).

51. F. Zha, H. Coster, and A. Fane, "A Study of Stability of Supported Liquid Membranes by Impedance Spectroscopy," J. Membr. Sci., 93, 255-271 (1994).

52. F.-F. Zha, A. G. Fane, and C. J. D. Fell, "Effect of Surface Tension Gradients on Stability of Supported Liquid Membranes," Ibid., 107, 75-86 (1995).

53. S. Chandrasekhar, Hydrodynamic and Hydromagnetic Stability, Clarendon Press, Oxford, 1961, pp. 491-499.

54. P. Walstra, "Formation of Emulsions," in Encyclopedia of Emulsion Technology, Vol. I: Basic Theory, Dekker, New York, NY, 1983, Chap. 2, pp. 57-127.

55. E. Gopal, "Principles of Emulsion Formation," in Emulsion Science (P. Sherman, Ed.), Academic Press, London, 1968, pp. 23-43.

56. T. Shinho, T. Yamaguchi, H. Yanagishita, K. Sakaki, D. Kitamoto, and M. Sugiura, "Supported Liquid Membranes for Enantioselective Transport of Amino Acids Mediated by Chiral Crown Ether-Effect of Membrane Solvent on Transport Rate and Membrane Stability," J. Membr. Sci., 84, 241-248 (1993).

57. M. Wienk, T. Stolwijk, E. Sudhölter, and D. Reinhoudt, "Stabilization of Crown Ether Containing Supported Liquid Membranes," J. Am. Chem. Soc., 112, 797-801 (1990).

58. W. van Straaten-Nijenhuis, "Macrocyclic Receptors as Selective Carriers in Membrane Transport," Ph.D. Thesis, University of Twente, 1992.

59. W. Nijenhuis, J. Walhof, E. Südholter, and D. Reinhoudt, "Lipophilic Diaza Crown Ethers in Supported Liquid Membranes: Influence of pH on Transport Rates and Membrane Stability," Recl. Trav. Chim. Pays-Bas, 110, 265-70 (1991).

60. D. Takigawa, "The Effect of Porous Support Composition and Operating Parameters 
on the Performance of Supported Liquid Membranes," Sep. Sci. Technol., 27(3), 325-339 (1992).

61. D. Takigawa, The Effect of Porous Support Composition and Operating Parameters on the Performance of Supported Liquid Membranes, Report, Los Alamos National Laboratory, LA-12027-MS, 1991; Chem. Abstr., 115, 281466 (1991).

62. M. Ashraf Chaudry, N. Islam, and N. Rehman, "Transport of U(VI) Ions in High Concentrations across Coupled Transport TBP-Kerosene Oil Supported Liquid Membranes," J. Radioanal. Nucl. Chem., 185(2), 387-399 (1994).

63. M. Tanigaki, M. Ueda, and W. Eguchi, "Facilitated Transport of Zinc Chloride through Hollow Fiber Supported Liquid Membrane. Part 2. Membrane Stability," Sep. Sci. Technol., 23, 1161-1169 (1988).

64. M. Teramoto and H. Tanimoto, "Mechanism of Copper Permeation through Hollow Fiber Liquid Membranes," Ibid., 18(10), 871-892 (1983).

65. T. Saito, "Deterioration of Liquid Membrane and Its Improvement in Permeation Transport of $\mathrm{Zn}$ (II) Ion through a Supported Liquid Membrane Containing a Bathocuproine," Ibid., 27(1), 1-9 (1992).

66. R. Chiarizia, E. Horwitz, P. Rickert, and K. Hodson, "Application of Supported Liquid Membranes for Removal of Uranium from Groundwater," Ibid.. 25(13-15), 1571-1586 (1990).

67. K. Fujinawa, M. Akiyama, I, Akiba, H. Adachi, N. Imaishi, and S. Hozawa, "Development of a Long-Life Supported Liquid Membrane," Kagaku Kogaku Ronbunshu, 15(1), 159-165 (1989); Chem. Abstr., 110, 97756b (1989).

68. L. Bromberg, G. Levin, and O. Kedem, "Transport of Metals through Gelled Supported Liquid Membranes Containing Carrier," J. Membr. Sci., 7l, 41-50 (1992).

69. G. Levin and L. Bromberg, "Gelled Membrane Composed of Dioctyldithiocarbamate Substituted on Poly(Vinylchloride) and Di(2-ethyl-hexyl)dithiophosphoric Acid," $J$. Appl. Polym. Sci., 48, 335-341 (1993).

70. L. Boyadzhiev, E. Bezenshek, and Z. Lazarova, "Removal of Phenol from Waste Water by Double Emulsion Membranes and Creeping Film Pertraction," J. Membr. Sci., 21, 137-144 (1984).

71. L. Boyadzhiev and Z. Lazarova, "Study on Creeping Film Pertraction. Recovery of Copper from Diluted Aqueous Solutions," Chem. Eng. Sci., 42(5), 1131-1135 (1987).

72. L. Boyadzhiev, "Liquid Pertraction or Liquid Membranes: State of the Art," Sep. Sci. Technol., 25(3), 187-205 (1990).

73. Z. Lazarova, "Pertraction mit flüssigen Filmen-Möglichkeiten und Perspektiven," Chem, Tech., 43(9), 332-336 (1991).

74. Z. Lazarova, "Extraction of Organic Solutes by Liquid Membranes," Solv. Extr. Ion Exch., $11(3), 497-503$ (1993).

75. L. Boyadzhiev and S. Alexandrova, "Dephenolation of Phenol-Containing Waters by Rotating Film Pertraction," Sep. Sci. Technol, 27(10), 1307-3017 (1992).

76. L. Boyadhiev and K. Dimitrov, "Recovery of Silver from Nitrate Solution by Means of Rotating Film Pertractor," J. Membr. Sci., 68, 137-143 (1994).

77. M. Teramoto, N. Tohno, N. Ohnishi, and H. Matsuyama, "Development of a SpiralType Flowing Liquid Membrane with High Stability and Its Application to the Recovery of Chromium and Zinc," Sep. Sci. Technol., 24(12-13), 981-999 (1989).

78. M. Teramoto, H. Matsuyama, T. Yamashiro, and S. Okamoto, "Separation of Ethylene from Ethane by a Flowing Liquid Membrane." J. Membr. Sci., 45, 115-136 (1989).

79. M. Teramoto, H. Matsuyama, and T. Yonehara, "Selective Facilitated Transport of Benzene across Supported Liquid Membranes Containing Silver Nitrate as Carrier," Ibid., 50, 269-284 (1990). 
80. S. Schlosser and I. Rothová, "A New Type of Hollow-Fiber Pertractor," Sep. Sci. Technol., 29(6), 765-780 (1994).

81. A. Sengupta, R. Basu, and K. K. Sirkar, "Separation of Solutes from Aqueous Solutions by Contained Liquid Membranes," AIChE J., 34(10), 1698-1708 (1988).

82. A. Sengupta, R. Basu, R. Prasad, and K. K. Sirkar, "Separation of Liquid Solutions by Contained Liquid Membranes," Sep. Sci. Technol., 23(12-13), 1735-1751 (1988).

83. R. Basu and K. K. Sirkar, "Hollow Fiber Contained Liquid Membrane Separation of Citric Acid," AIChE J., 37(3), 383-393 (1991).

84. S. Majumdar, K. Sirkar, and A. Sengupta, "Hollow-Fiber Contained Liquid Membrane," in Membrane Handbook (W. Ho and K. Sirkar, Eds.), Van Nostrand Reinhold, New York, NY, 1992, Chap. 42, pp. 764-808.

85. B. Kim, "Membrane-Based Solvent Extraction for Selective Removal and Recovery of Metals," J. Membr. Sci., 21, 5-19 (1984).

86. Z. Gu, Q. Wu, Z. Zhang, X. Li, Y. Jiang, C. Tang, and P. Lin, "Laboratory and Pilot Plant Test of Yttrium Recovery from Wastewater by Electrostatic Pseudo Liquid Membrane," Ibid., 93, 137-147 (1994).

87. X.-J. Yang, Z.-M. Gu, and D.-X. Wang, "Extraction and Separation of Scandium from Rare Earths by Electrostatic Pseudo Liquid Membrane," Ibid., 106, 131-145 (1995).

88. O. Kedem and L. Bromberg, "Ion-Exchange Membranes in Extraction Processes," Ibid., 78, 255-264 (1993).

89. Y. Isono, K. Fukushima, T. Kawakatsu, and M. Nakajima, "New Selective Perstraction System with Charged Membrane," Ibid., 105, 293-297 (1995).

Received by editor January 16, 1996 